\title{
Deployment-related stress and trauma in Dutch soldiers returning from Iraq
}

\author{
Prospective study
}

IRIS M. ENGELHARD, MARCEL A. VAN DEN HOUT, JOS WEERTS,
ARNOUD ARNTZ, JOOP J. C. M. HOX and RICHARD J. MCNALLY

\author{
Background Some questionnaire \\ studies have shown increased mental \\ health problems, including probable post- \\ traumatic stress disorder (PTSD), in \\ soldiers deployed to Iraq.
}

\begin{abstract}
Aims To test prospectively whether such problems change over time and whether questionnaires provide accurate estimates of deployment-related PTSD compared with a clinical interview.
\end{abstract}

\begin{abstract}
Methods Dutch infantry troops from three cohorts completed questionnaires before deployment to Iraq $(n=479)$, and about 5 months $(n=382,80 \%)$ and 15 months ( $n=331,69 \%)$ thereafter. Posttraumatic stress disorder was evaluated by questionnaire and clinical interview.
\end{abstract}

Results There were no group changes for general distress symptoms. The rates of PTSD for each cohort were 21,4 and $6 \%$ based on questionnaires at 5 months. The deployment-related rates of PTSD based on the clinical interview were 4,3 and $3 \%$.

\section{Conclusions There was a specific effect of deployment on mental health for a small minority. Questionnaires eliciting stress symptoms gave substantial overestimations of the rate of PTSD.}

Declaration of interest None. Funding detailed in Acknowledgements.
On 22 May 2003 the United Nations called on its member states to help reconstruct Iraq and over 30 countries have contributed soldiers to the coalition. As of 21 November 2006, there were 3113 deaths of coalition soldiers from 19 nations (http:// edition.cnn.com/SPECIALS/2003/iraq/forces. casualties). Concerns have been raised about the mental health costs for service personnel. Hoge et al, 2004 estimated that $12.9 \%$ of US soldiers involved in combat operations in Iraq had post-traumatic stress disorder (PTSD), which was higher than in a sample tested before their deployment (5\%). Hotopf et al (2006) estimated a $4 \%$ incidence of PTSD among UK armed forces returning from Iraq, which was similar to a non-deployed sample. Hacker Hughes et al (2005) revealed a lower score for mental health problems after deployment, compared with before, for the UK Air Assault Brigade but the response rate was low.

These studies provide clues about the impact of deployment to Iraq, but two studies were cross-sectional and did not include the participants' health status predeployment. This may lead to an overestimation of the effects of deployment on stress symptoms (Hotopf \& Wessely, 2005; Hedeker \& Gibbons, 2006). Two recent prospective studies showed that PTSD was uncommon $(<3.2 \%)$ for UK armed forces (Rona et al, 2006) and PTSD symptoms increased modestly for US armed forces (Vasterling et al, 2006) after deployment. These prior cross-sectional and prospective studies investigated PTSD using questionnaires, but the DSM-IV diagnostic criteria for PTSD require that symptoms interfere in important ways with the individual's functioning, which is routinely checked in diagnostic interviews but not questionnaires. Failing to take this into account may result in overestimated rates of deployment-related PTSD (see Regier et al, 1998; Frueh et al, 2000; Ismail et al, 2002; Wessely, 2004; McNally, 2006). This was recently found in a re-analysis of PTSD among Vietnam veterans. In 1988 the estimated lifetime prevalence rate for PTSD was $30.9 \%$ and the current rate (11-12 years after the war) $15.2 \%$. Dohrenwend et al (2006) consulted archival data and eliminated PTSD which was unrelated to war events and PTSD without impairment. This decreased estimates of lifetime and current (late 1980s) PTSD to 18.7 and $9.1 \%$ respectively, thereby confirming the suspicion of critics who believed the original rates to be implausibly high (McNally, 2007).

This paper reports a prospective study of deployment-related mental health problems in three Dutch infantry cohorts stationed in the Iraqi province of AlMuthanna under British command. Mental health measures were collected before deployment, and 5 months and 15 months thereafter. We tested for individual changes in these variables over time as well as potential predictors for changes. To compare assessment methods, we established PTSD rates by questionnaire and clinical interview.

\section{METHOD}

\section{Participants}

About 6 weeks before their deployment, 481 Royal Netherlands Army troops were asked to participate in this study. They were from three infantry battalions that rotated successively in three deployment phases, each lasting about 4 months, designated Stabilisation Force Iraq (SFIR) 3, 4 and 5. These took place from 15 March 2004 to 15 March 2005. During this period, about 4990 Dutch soldiers were deployed to Iraq. They sustained two casualties. An Armoured Infantry Battalion was deployed on SFIR 3, and two battalions of the Air Assault Brigade were deployed on SFIR 4 and 5. Their main duties were to create and maintain stability and peace, and assist in reconstruction. At various sites, troops available during their preparation programme were told about the aim and general procedures of the study by their commanding officers. They met the principal investigator (I.M.E.) or research assistant a few days later, who gave full (oral and written) information about the study. Participation was voluntary without financial compensation. Participants were told that commanders would be informed only about pooled results. Two soldiers refused and 479 agreed to participate, 
including 214 SFIR 3 soldiers, 169 SFIR 4 soldiers and 96 SFIR 5 soldiers.

\section{Procedures}

About 5 months after their deployment, questionnaires about potentially traumatic events in Iraq and current mental health problems were administered. The Structured Clinical Interview for DSM-IV (SCID; First et al, 1996) was then administered by a trained clinical psychologist (about 20 interviews were carried out by graduate students), who did not know the responses to the questionnaires. At about 15 months, measures for current problems were administered as well as the face-toface SCID. At 5 months, most questionnaires were given to small groups at a base, and at 15 months $31 \%$ of questionnaires were sent by post. Non-response was partly a result of soldiers being on leave, attending a training course, or being posted to new units. The institutional review board of Maastricht University approved the study.

\section{Measures}

Symptoms of common mental health problems were measured with the 90-item Symptom Checklist (SCL-90; Arrindell \& Ettema, 2003). Each item was rated on a 1 (not at all) to 5 (very much) scale. We focused on sub-scales of anxiety (10 items), depression (17 items), somatic complaints (12 items) and sleeping problems (3 items), and used the SCL-90 score for general distress. Prior life events were assessed with a 17-item checklist that included road accidents, sudden death of a loved one, fire and being robbed. A score was compiled of all endorsed items.

Events in Iraq were assessed with the 21-item Potentially Traumatizing Events Scale (Litz et al, 1997; Maguen et al, 2004), which is derived partly from the Combat Exposure Scale, and measures the frequency of exposure to war-zone-related stressors. The scale was adjusted for use in Iraq by deleting one item (patrolling areas where there were land mines) and adding two (being informed of a Dutch soldier who got killed and having injured civilians due to own action). For each item experienced, individuals rated how negative it was for them on a Likert scale. We calculated the number of reported events as well as the number of events appraised as moderate to extremely negative, and used both in the analyses.
Symptoms of PTSD were measured with the 17-item PTSD Symptom Scale (PSS), which has proven to be effective for screening for PTSD (Foa et al, 1993; Wohlfarth et al, 2003; Coffey et al, 2006). Each symptom was rated from 0 (not at all) to 3 (very much) for the past month. We used two case definitions for PTSD: a broad definition that follows diagnostic symptom criteria (a minimal number of symptoms had to be rated at least 'some of the time'), and a stricter definition for which a cut-off score of 14 was used (Coffey et al, 2006). Both scoring methods have been used previously. After completing the PSS, participants were asked to rate their distress and functional impairment in different areas of their lives (work, home, interpersonal relationships) on a 4-point scale (0 not at all, 3 very much). Selfreports of impairment were compared with SCID-based assessments which include the DSM-IV symptoms and questions about subjective distress and functional impairment caused by these symptoms.

\section{Statistical analysis}

Analyses were performed with SPSS (version 11.5) and HLM (version 5), both for Windows. Missing items were estimated by observed item means if no more than two items per scale were missing. Demographic variables were compared between the cohorts. We tested whether there were systematic differences between individuals who did or did not drop out on characteristics from earlier measurement occasions. The rates of potentially traumatic events were assessed and the mean scores on mental health scales before deployment and at 5 and 15 months were calculated. These variables were non-normally distributed and therefore statistical tests were based on robust standard errors (sandwich estimates; White, 1982). A within-class hierarchical linear model was used to test whether the level of mental health symptoms varied across the three assessments for the three cohorts. The slopes of the time variables were allowed to vary across individuals, to test whether the variance components for the intercept and the regression slope for the time variables were significant. If these were significant, we sought to explain this variance by running separate betweencohort models to examine the effects of demographic and background factors (age, gender, partner status, education, temporary $v$. permanent contract, number of previous missions, previous life events, rank, cohort), number of potentially traumatic events in Iraq, and number of events rated as negative. The model was run again without non-significant predictors to reduce error. Rates of PTSD were calculated based on the questionnaire and SCID. We tested to what extent the PTSD rates were predicted by pre-deployment PTSD and general distress symptoms, prior life events, and number of events in Iraq by logistic regression analysis. Odds ratios with $95 \%$ confidence intervals were generated. All statistical tests of significance were twotailed at the $\alpha=0.05$ level.

\section{RESULTS}

Table 1 shows the characteristics of the three cohorts. The SFIR 3 and 5 cohorts were older than SFIR 4 and had more prior deployments. The SFIR 5 cohort had more officers. About 5 months after deployment, $382(80 \%)$ soldiers completed questionnaires and $339(71 \%)$ took part in the SCID. At about 15 months, 331 soldiers (69\%) completed questionnaires and 203 $(42 \%)$ did the SCID. Given the low response rates, the SCID data at 15 months are not considered. Soldiers who did not complete questionnaires at 5 months had slightly more prior missions than those who did. There were no significant differences on other pre-deployment measures. Responders and non-responders at 15 months did not differ on variables assessed earlier. We therefore treated the drop-outs as occasions missing at random.

Table 2 shows that cohorts SFIR 3 and 4 reported more potentially traumatic events in Iraq than SFIR $5(F(2,370)=$ $60.73, P<0.001)$. The number of events rated as negative was higher for SFIR 3 and 5 than for SFIR $4\left(\chi^{2}(2)=14.65\right.$, $P=0.001$ ).

Table 3 indicates scores on mental health scales before and after deployment. The mean levels of anxiety, depression, somatic complaints, sleeping problems and general distress did not vary over time for the cohorts. The variance components for the intercept and the regression slope for the time variables were significant for all mental health scales, which means that individuals had different initial states as well as different rates of change. We sought to explain this variance. The final model for this analysis showed that prior life events and the SFIR 3 cohort (Armoured Infantry 
Table I Characteristics of the three cohorts

\begin{tabular}{|c|c|c|c|}
\hline & \multicolumn{3}{|c|}{ Cohort } \\
\hline & $\begin{array}{c}\text { SFIR } 3 \\
(n=2 \mid 4)\end{array}$ & $\begin{array}{c}\text { SFIR } 4 \\
(n=169)\end{array}$ & $\begin{array}{l}\text { SFIR } 5 \\
(n=96)\end{array}$ \\
\hline Age, years: mean (s.d.) & $23.06(4.49)$ & $21.63(3.54)$ & $22.73(4.02)$ \\
\hline Male gender, $n(\%)$ & $204(95)$ & $169(100)$ & $94(98)$ \\
\hline \multicolumn{4}{|l|}{ Marital status, $n$ (\%) } \\
\hline Single & $167(78)$ & $132(78)$ & $73(78)$ \\
\hline Married/cohabiting & $47(22)$ & $37(22)$ & $21(22)$ \\
\hline Education, $n$ (\%) & $14(7)$ & $3(2)$ & $4(4)$ \\
\hline Primary school & $194(91)$ & $162(96)$ & $88(92)$ \\
\hline Secondary school & $5(2)$ & $3(2)$ & $4(4)$ \\
\hline \multicolumn{4}{|l|}{ College } \\
\hline \multicolumn{4}{|l|}{ Rank, $n$ (\%) } \\
\hline Non-commissioned officer & $15(7)$ & $16(10)$ & $16(17)$ \\
\hline Commissioned officer & $2(I)$ & $2(I)$ & $4(4)$ \\
\hline Other rank & $196(92)$ & $151(89)$ & $76(79)$ \\
\hline \multicolumn{4}{|l|}{ Prior missions, $n$ (\%) } \\
\hline 0 & $13 \mid(61)$ & 12I (72) & $51(53)$ \\
\hline 1 & $52(24)$ & $28(17)$ & $29(30)$ \\
\hline $2-4$ & 31 (I5) & $20(I I)$ & $16(17)$ \\
\hline \multicolumn{4}{|l|}{ Contract status, $n(\%)$} \\
\hline Permanent & $16(8)$ & $6(4)$ & $17(18)$ \\
\hline Temporary & $197(92)$ & $163(96)$ & $79(82)$ \\
\hline
\end{tabular}

SFIR, Stabilisation Force Iraq.

I. Some data were missing for I person from SFIR 3 and 2 persons from SFIR 5 .

$v$. two Air Assault cohorts) were related to more pre-deployment symptoms. Although SFIR 3 was associated with pre-deployment symptoms, levels were still (very) low compared with norms for the civilian population (Arrindell \& Ettema, 2003). The number of events in Iraq appraised as negative showed a strong linear relationship with slope estimates in somatic complaints and PTSD symptoms. The number of events experienced and the demographic and military characteristics were not significant (data not reported).

Table 4 shows that the PTSD estimates based on the questionnaire (PSS) 5 months after deployment were higher for the Armoured Infantry cohort compared with the other two cohorts. This difference disappeared after controlling for pre-deployment symptoms and reported harmful exposure in Iraq. Overall, the PTSD estimate was about 2 times higher than the unadjusted SCID rates. This was similar for participants who completed both the PSS and SCID: unadjusted PTSD rates were $41 \%$ lower than the PSS estimates. When using the stricter cut-off score, the questionnaire rates dropped (to 17,4 and $0 \%$ respectively), but were still 1.5 times greater than the unadjusted SCID rates. A third of the 'false-positives' endorsed PTSD symptoms after stressful life events (e.g. social exclusion, viral infection, arguments with colleague, problems in relationship). On the basis of the SCID we were able to distinguish the current deployment-related rate of PTSD from PTSD with other origins (i.e. death of a relative and an earlier deployment) and PTSD with no more than slight impairment. This reduced the overall unadjusted SCID rates by about half. Soldiers with full PTSD reported significantly more functional impairment on the Likert scale than the others $(U=2611$, $P<0.001)$. Only 2 out of 12 participants with full PTSD according to diagnostic interview marked at least 'moderate' impairment on the self-rated functional impairment Likert scale; 10 out of 12 with full PTSD reported at least 'a little bit' of impairment, but so did $68 \%$ of the false-positives. The PTSD rates were significantly associated with pre-deployment PTSD symptoms, earlier life events and the number of events on deployment rated as negative (data not reported).

\section{DISCUSSION}

\section{Main findings}

The main findings of the study were that (a) levels of general distress remained relatively stable from before to after deployment; (b) the Armoured Infantry cohort showed a higher PTSD estimate by questionnaire than the Air Assault Brigade cohorts owing to more pre-deployment symptoms and more reported harmful exposure in Iraq; (c) unadjusted PTSD rates from diagnostic interview were $41 \%$ lower than estimates from the questionnaire; (d) interview rates of PTSD were nearly halved after adjustment for PTSD which was unrelated to deployment and functional impairment; (e) a small minority of soldiers showed full-blown deployment-related PTSD.

The deployment-related rates of PTSD were much lower when the SCID was used as a diagnostic tool. The questionnaire could have led to inflated rates of symptoms because several individuals endorsed symptoms stemming from traumatic events which were unrelated to deployment (e.g. death of a relative), or from stressful but seemingly non-catastrophic events. Other studies have also linked non-traumatic life events to PTSD symptoms (see McNally, 2003). Moreover, PTSD questionnaires assess symptoms during the past month and fail to control for pre-existing stress and psychopathology. The PTSD arousal symptoms (e.g. difficulty sleeping, irritability, concentration problems) are not specific for the disorder, and may very well have been present before deployment (Clark et al, 1994).

\section{Other studies}

The questionnaire-based estimate of PTSD after deployment to Iraq has been documented in a few previous studies, but comparison is limited by differences in populations studied, sampling and response rates. Hoge et al (2004) reported high levels of combat exposure in US infantry soldiers and used a broad symptom-based definition that resulted in a PTSD estimate of $18 \% 3-$ 4 months after their return from Iraq. The PTSD estimate in our SFIR 3 (Armoured Infantry) cohort is similar (17-21\%). Hotopf et al (2006) reported a rate of $4 \%$ in a random UK military sample that reported less trauma exposure. Hacker Hughes et al (2005) found that the PTSD estimate was $2 \%$ in a sample of the UK Air Assault Brigade. This is in the range we found for 
Table 2 Potentially traumatic events experienced by soldiers in Iraq

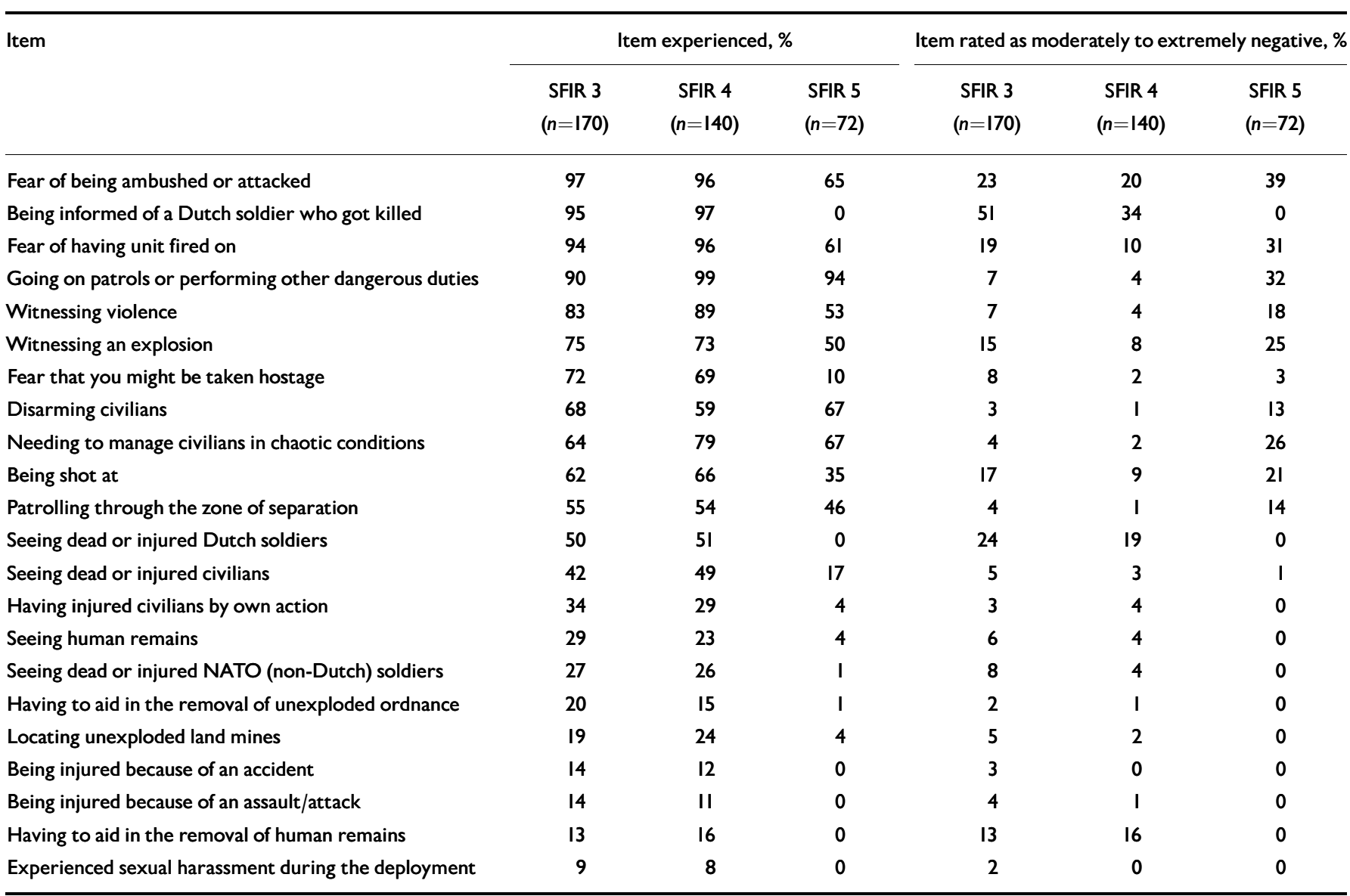

SFIR, Stabilisation Force Iraq.

Air Assault Brigade cohorts (0-6\%). For some, psychological symptoms may actually decrease, which has been shown previously in a UK study (Hacker Hughes et al, 2005). The lack of change over time after deployment in our study is in line with other UK research (Hotopf et al, 2006), but not with the study of Hoge et al (2006) which suggested that rates of PTSD increase in the months after deployment.
Various reasons have been proposed for the different outcomes of US and UK studies, including differences in trauma severity and healthcare systems (Hotopf et al, 2006).

\section{Implications}

Can the present findings be extrapolated to other types of trauma and civilian populations? We do not know whether our PTSD rates may be generalised to the military populations studied: although our response rates were exceptionally high, the convenience sampling method was less desirable than random sampling. However, there are no empirical or theoretical reasons to assume that the pattern of results would be different for different samples or populations. Population-level screening for PTSD is important to identify healthcare needs,

Table 3 Scores on mental health scales for the three cohorts

\begin{tabular}{|c|c|c|c|c|c|c|c|c|c|}
\hline & \multicolumn{3}{|c|}{ Before deployment } & \multicolumn{3}{|c|}{5 months after deployment } & \multicolumn{3}{|c|}{15 months after deployment } \\
\hline & $\begin{array}{c}\text { SFIR } 3 \\
(n=2 \mid 4)\end{array}$ & $\begin{array}{c}\text { SFIR } 4 \\
(n=169)\end{array}$ & $\begin{array}{l}\text { SFIR } 5 \\
(n=96)\end{array}$ & $\begin{array}{c}\text { SFIR } 3 \\
(n=170)\end{array}$ & $\begin{array}{c}\text { SFIR } 4 \\
(n=\mid 40)\end{array}$ & $\begin{array}{l}\text { SFIR } 5 \\
(n=72)\end{array}$ & $\begin{array}{c}\text { SFIR } 3 \\
(n=152)\end{array}$ & $\begin{array}{c}\text { SFIR } 4 \\
(n=120)\end{array}$ & $\begin{array}{l}\text { SFIR } 5 \\
(n=59)\end{array}$ \\
\hline \multicolumn{10}{|l|}{ SCL-90 } \\
\hline Anxiety score: mean (s.d.) & $11.6(3.0)$ & $10.9(1.7)$ & $10.7(1.6)$ & $11.2(3.3)$ & $10.7(1.8)$ & $10.6(1.4)$ & $11.4(3.1)$ & $11.0(2.6)$ & $10.2(0.5)$ \\
\hline Depression score: mean (s.d.) & $18.9(4.8)$ & $17.7(3.1)$ & $17.6(2.6)$ & $19.0(5.9)$ & $18.0(4.7)$ & $17.4(2.9)$ & $19.2(6.8)$ & $18.2(5.8)$ & $16.7(1.4)$ \\
\hline Somatisation score: mean (s.d.) & $14.4(3.5)$ & $13.3(2.3)$ & $13.6(2.2)$ & $14.0(3.2)$ & $13.4(3.0)$ & $13.4(2.1)$ & $14.3(4.5)$ & I3.5 (3.0) & $12.8(1.7)$ \\
\hline Sleeping problems score: mean (s.d.) & $3.9(1.9)$ & $3.4(I .1)$ & $3.4(0.8)$ & $4.2(2.2)$ & $3.4(1.2)$ & $3.6(1.5)$ & $4.2(2.3)$ & $3.3(0.7)$ & $3.2(0.7)$ \\
\hline PSS symptom severity score: mean (s.d.) & $3.0(3.8)$ & $N / A$ & $3.0(4.4)$ & $6.5(7.1)$ & $3.7(4.4)$ & $2.1(3.0)$ & $5.0(6.9)$ & $2.8(5.0)$ & $1.2(2.1)$ \\
\hline
\end{tabular}

SCL-90, 90 -item Symptom Checklist; PSS, Post-traumatic Stress Disorder Symptom Scale; NA, not available. 


\begin{tabular}{|c|c|c|c|c|c|c|c|c|c|}
\hline & \multicolumn{3}{|c|}{ SFIR 3} & \multicolumn{3}{|c|}{ SFIR 4} & \multicolumn{3}{|c|}{ SFIR 5} \\
\hline & $n / N$ & $\%$ & $95 \% \mathrm{Cl}$ & $n / N$ & $\%$ & $95 \% \mathrm{Cl}$ & $n / N$ & $\%$ & $95 \% \mathrm{Cl}$ \\
\hline PSS & $36 / 170$ & 21 & $15-28$ & $6 / 140$ & 4 & $2-9$ & $4 / 72$ & 6 & $2-14$ \\
\hline SCID unadjusted & $17 / 148$ & 12 & $7-18$ & $4 / 129$ & 3 & $\mathrm{I}-8$ & $2 / 62$ & 3 & $0-11$ \\
\hline SCID adjusted for deployment-unrelated PTSD & $13 / 148$ & 9 & $5-15$ & $4 / 129$ & 3 & $\mathrm{I}-8$ & $2 / 62$ & 3 & $0-11$ \\
\hline PTSD and lack of functional impairment & & & & & & & & & \\
\hline
\end{tabular}

PTSD, post-traumatic stress disorder; PSS, PTSD Symptom Scale; SCID, Structured Clinical Interview for DSM-IV.

and self-report measures such as the PSS have reasonable sensitivity and specificity (see Coffey et al, 2006). However, when PTSD rates are low, as in the present cohort, it would be unwise to implement questionnaire-based screening (see also Rona et al, 2006). For clinical purposes, the rate of false-positives is less of a concern because the initial questionnaires can be followed by a comprehensive diagnostic interview. Such a two-step approach has been recommended to identify PTSD (Shrout $e t$ $a l$, 1986). However, in epidemiological studies, the impact of traumatic events on mental health is often determined by merely examining whether or not participants meet symptom criteria for PTSD on a questionnaire. Our findings suggest that many people screened positive for PTSD may actually not have the disorder. Other studies have also shown that questionnaires provide higher estimates of ill health than clinical assessment: symptoms may signify disorder, but then again they might not (see Frueh et al, 2000; Wessely, 2004; Hotopf $\&$ Wessely, 2005). Healthcare needs might be much lower than expected on the basis of questionnaires.

A striking finding was that for $36.8 \%$ of soldiers showing the full PTSD symptom pattern on the SCID, symptoms did not produce more than slight impairment in their lives. This is in line with a re-analysis of PTSD among Vietnam veterans, in which individuals exposed to traumatic events and who experienced minimal symptoms for the diagnosis might very well have qualified as having PTSD despite living well-adjusted, productive lives (Dohrenwend et al, 2006). It also fits well with a recent major re-analysis of two large US community surveys in which previously unused data on the clinical significance of symptoms were used to recalculate prevalence rates of mental disorder. Prevalence rates of any disorder were lowered by 17 and 32\% (depending on the survey; Narrow et al, 2002). Hoge et al (2004) also recalculated the PTSD rates after combat in Iraq on the basis of functional impairment or greater severity, and found that this decreased symptombased PTSD rates by nearly $30 \%$ (from 18 to $12.9 \%$ ). The DSM-IV classification system requires this functional impairment to differentiate symptoms from disorder, but population-based studies typically do not consider this criterion. Unfortunately, the system lacks objective criteria to determine impairment, and more work should be done to define when impairment becomes clinically significant.

\section{Limitations}

The present study does not provide information about the natural course of PTSD and functional impairment extending over 15 months. Despite considerable effort, the sample interviewed at follow-up was small, owing largely to the high turnover of personnel. This was also responsible for reduced sample sizes in previous studies (Hotopf \& Wessely, 2005). Longitudinal evaluations of civilian populations suggest that PTSD symptoms decrease substantially within the first year, but little is known about the predictive validity of mild and sub-threshold forms of PTSD for soldiers on active duty. There is evidence from the National Comorbidity Study that a proportion of people with 'mild' mental disorders had worse clinical outcomes up to 10 years later (Kessler et al, 2003). Similar longitudinal studies are needed for military populations. Some active soldiers may not experience functional impairment until they leave the military. If such predictive validity were found, the need for interventions might be considered on the basis of functional impairment as well as the risk of progression from a mild to a more severe disorder. This could have great public health importance. Clearly, these issues await future research.

There are some issues of sample size and power in our study. The use of a complex multilevel analysis and the presence of attrition is an obstacle for estimating power for the analysis method used. However, a one-way analysis of variance at the first measurement (before deployment) with a sample size of 479 achieves a power of 0.99 for medium effects and 0.48 for small effects. Analysis at 15 months with a sample size of 331 achieves a power of 0.98 for medium effects and 0.35 for small effects. The multilevel analysis should have at least this much power and the power to detect medium size effects should be very high. However, these results suggest that the study has only weak power for detecting small effects.

\section{Future directions}

Understanding PTSD from an epidemiological perspective is vital for estimating the likely need for healthcare services and information. This study shows that some individuals meet the PTSD symptom criteria but lead productive lives despite stress, and that some PTSD is triggered by causes unrelated to deployment. Not considering these aspects leads to inflated rates of deployment-related PTSD.

\section{ACKNOWLEDGMENTS}

We thank Marieke van Baars and Lotte Bamelis for assistance with data collection, Erik Schouten for help with analyses, and the commanders and troops for their time and effort. This study was supported by a grant from the Veterans Institute (Doorn, The Netherlands) and an award by the Netherlands Organisation for Scientific Research to Iris $M$. Engelhard (Innovational Research Incentive VENI Scheme 016.045.106). We thank (representatives of) the Netherlands Ministry of Defense for their cooperation, and in particular the Afdeling Individuele Hulpverlening $(\mathrm{AlH})$ and Col MD Kees ljzerman. 


\section{REFERENCES}

Arrindell, W. A. \& Ettema, J. H. M. (2003) Symptom Checklist SCL-90. Swets \& Zeitlinger.

Clark, L. A., Watson, D. \& Mineka, S. (1994)

Temperament, personality, and the mood and anxiety disorders. Journal of Abnormal Psychology, 103, 103-116.

Coffey, S. F., Gudmundsdottir, B., Beck, J. G., et al (2006) Screening for PTSD in motor vehicle accident survivors using the PSS-SR and IES. Journal of Traumatic Stress, 19, 119-128.

Dohrenwend, B. P., Turner, J. B., Turse, N. A., et a (2006) The psychological risks of Vietnam for U.S. Veterans: a revisit with new data and methods. Science, 313, 979-982.

First, M. B., Spitzer, R. L., Gibbon, M., et al (1996) Structured Clinical Interview for DSM-IV Axis I Disorders (SCID) (Clinician Version). American Psychiatric Press.

Foa, E. B., Riggs, D. S., Dancu, C. V., et al (1993) Reliability and validity of a brief instrument for assessing post-traumatic stress disorder. Journal of Traumatic Stress, 6, 459-473.

Frueh, B. C., Hamner, M. B., Cahill, S. P., et al (2000) Apparent symptom overreporting in combat veterans evaluated for PTSD. Clinical Psychology Review, 20, 853885.

Hacker Hughes, J., Cameron, F., Eldridge, R., et al (2005) Going to war does not have to hurt: preliminary findings from the British deployment to Iraq. British Journal of Psychiatry, 186, 536-537.

Hedeker, D. \& Gibbons, R. D. (2006) Longitudinal Dato Analysis. Wiley.

Hoge, C. W., Castro, C. A., Messer, S. C., et al (2004) Combat duty in Iraq and Afghanistan, mental health problems, and barriers to care. New England Journal of Medicine, 35I, 13-22.

Hoge, C.W., Auchterlonie, J. L. \& Milliken, C. S. (2006) Mental health problems, use of mental health services, and attrition from military service after returning from deployment to Iraq or Afghanistan. JAMA, 295, 1023-1032.

IRIS M. ENGELHARD, PhD, MARCEL A.VAN DEN HOUT, PhD, Clinical and Health Psychology, Utrecht University; JOS WEERTS, MSc, Veterans Institute, Doorn; ARNOUD ARNTZ, PhD, Department of Medical, Clinical, and Experimental Psychology, Maastricht University; JOOP J. C. M. HOX, PhD, Methodology and Statistics, Utrecht University, The Netherlands; RICHARD J. MCNALLY, PhD, Department of Psychology, Harvard University, Boston, Massachusetts, USA

Correspondence: Dr Iris M. Engelhard, Clinical and Health Psychology, Utrecht University, PO Box 80140, 3508 TC Utrecht, The Netherlands. Email: i.m.engelhard@fss.uu.nl

(First received 20 December 2006, final revision 14 March 2007, accepted 28 March 2007)

Hotopf, M. \& Wessely, S. (2005) Can epidemiology clear the fog of war? Lessons from the 1990-91 Gulf War. International Journal of Epidemiology, 34, 791-800.

Hotopf, M., Hull, L., Fear, N. T., et al (2006) The health of UK military personnel who deployed to the 2003 Iraq war: a cohort study. Lancet, 367, 173I-174I.

Ismail, K., Kent, K., Brugha, T., et al (2002) The mental health of UK Gulf War veterans: phase 2 of a two phase cohort study. BMJ, 325, 576-579.

Kessler, R. C., Merikangas, K. R., Berglund, P., et al (2003) Mild disorders should not be eliminated from the DSM-IV. Archives of General Psychiatry, 60, III7-1122.

Litz, B. T., Orsillo, S. M., Friedman, M., et al (1997) Posttraumatic stress disorder associated with peacekeeping duty in Somalia for U.S. military personnel. American Journal of Psychiatry, 154, 178-184.

Maguen, S., Litz, B. T., Wang, J. L., et al (2004) The stressors and demands of peacekeeping in Kosovo: predictors of mental health response. Military Medicine, 169, 198-206.

McNally, R. J. (2003) Remembering Trauma. Harvard University Press.

McNally, R. J. (2006) Psychiatric casualties of war. Science, 313, 923-924.

McNally, R. J. (2007) Can we solve the mysteries of the National Vietnam Veterans Readjustment Study? Journal of Anxiety Disorders, 2I, 192-200.
Narrow, W. E., Rae, D. S., Robins, L. N., et al (2002) Revised prevalence estimates of mental disorders in the United States. Archives of General Psychiatry, 59, II5-123.

Regier, D. A., Kaelber, C. T., Rae, D. S., et al (1998) Limitations of diagnostic criteria and assessment instruments for mental disorder. Archives of General Psychiatry, 55, 109-115.

Rona, R.J., Hooper, R., Jones, M., et al (2006) Mental health screening in armed forces before the Iraq war and prevention of subsequent psychological morbidity: follow-up study. BMJ, 333, 991. doi: 10.1136 bmj.38985.610949.55

Shrout, P. E., Skodol A. E. \& Dohrenwend, B. P. (1986) A two-stage approach for case identification and diagnosis, first stage instruments. In Mental Disorders in the Community: Progress and Challenge (eds J. E. Barrett \& R. M. Rose), pp. 286-303. Guilford Press.

Vasterling, J.J., Proctor, S.P., Amoroso, P., et af (2006) Neuropsychological outcomes of Army personnel following deployment to the Iraq War. JAMA 296, 519-529.

Wessely, S. (2004) When being upset is not a mental health problem. Psychiatry, 67, 153-157.

White, H. (1982) Maximum likelihood estimation of miss-specified models. Econometrica, 50, I-25.

Wohlfarth, T. D., van den Brink, W., Winkel, F. W., et al (2003) Screening for posttraumatic stress disorder: an evaluation of two self-report scales among crime victims. Psychological Assessment, 15, 10I-119. 